\title{
Vertebral Bone Drilling (Puncture) Attenuates the Acute Pain Due to Vertebral Compression Fractures
}

\author{
Koichi Ota $^{1^{*}}$, Sosi Iwasaki ${ }^{2}$ \\ ${ }^{1}$ Department of Anesthesia, Ebetsu City Hospital, Ebetsu, Japan; ${ }^{2}$ Department of Anesthesiology, Sapporo Medical University, Sap- \\ poro, Japan. \\ Email: *kota1281@gmail.com
}

Received October $6^{\text {th }}, 2013$; revised January $6^{\text {th }}, 2014$; accepted January $17^{\text {th }}, 2014$

Copyright (C) 2014 Koichi Ota, Sosi Iwasaki. This is an open access article distributed under the Creative Commons Attribution License, which permits unrestricted use, distribution, and reproduction in any medium, provided the original work is properly cited. In accordance of the Creative Commons Attribution License all Copyrights (C) 2014 are reserved for SCIRP and the owner of the intellectual property Koichi Ota, Sosi Iwasaki. All Copyright (C) 2014 are guarded by law and by SCIRP as a guardian.

\section{ABSTRACT}

Purpose: The Investigational Vertebroplasty Efficacy and Safety Trial (INVEST), a randomized blinded controlled study of Vertebroplasty, demonstrated similar improvements in pain between blinded Vertebroplasty and sham-Vertebroplasty groups. The result from the RCT study suggested that the observed efficacy of the Vertebroplasty procedure, instead of representing the cement-mediated reduction in pain, may relate to the vertebral bone drilling per se. The aim of this study was to demonstrate the effectiveness of pain relief of vertebral bone drilling at the site of painful osteoporotic vertebral compression fractures in the acute phase. Materials and Methods: Twenty-six patients with painful osteoporotic compression fractures underwent the vertebral bone drilling. We assessed primary outcome measures in the NRS pain score and RDQ score at day $\mathbf{0}$ and 3 following the drilling. Comparisons were made by using Wilcoxon signed rank test. Results: The mean baseline NRS and RDQ score, and the mean NRS and RDQ score at day 3 were $7.3 \pm 1.2,15.7 \pm 4.2,4.6 \pm 1.4,7.3 \pm 2.2$, respectively. Among the patients, we detected significant improvements in NRS pain score and RDQ score at day 3 following the drilling compared with day $0(P<0.001)$. Conclusion: Vertebral bone drilling at the site of painful vertebral compression fractures alleviated the intractable pain due to osteoporotic vertebral compression fractures.

\section{KEYWORDS}

Vertebral Bone Drilling; Osteoporosis; Vertebral Compression Fractures; Acute Pain; Vertebroplasty

\section{Introduction}

Vertebroplasty was first described in 1987 [1]. It became a general treatment for symptomatic vertebral compression fractures. Vertos II [2] and FREE trial [3], which compared Vertebroplasty or Kyphoplasty to traditional conventional management, show the efficacy of Vertebroplasty for painful vertebral compression fractures.

On the contrary, two independent placebo-controlled RCT studies [4,5] found Vertebroplasty to be equivalent to a sham intervention. The sham procedure simulated the Vertebroplasty without injection of cement. The two groups were a similar reduction in pain, and improve-

\footnotetext{
*Corresponding author.
}

ments in back pain-related disability in acute and chronic phase.

Kohashi et al. [6] reported that vertebral body decompression (puncture) which means the Vertebroplasty without cement decreased the pain and improved the back pain-related disability. On the contrary, periosteum vertebral infiltration of local anesthetics did not reduce the intractable pain due to vertebral compression fracture [7]. These reports show that the vertebral Bone Drilling (B.D.) is essential for attenuation of pain due to vertebral compression fractures. We designed this study for assessments of vertebral B.D. for the intractable pain induced by osteoporotic vertebral compression fractures in the acute stage. 


\section{Materials and Methods}

\subsection{Study Participants}

Consecutive patients presenting to the pain clinic for painful vertebral compression fractures were screened for enrollment between December 2009 and November 2010. We obtained institutional review board approval and informed consent for all patients. Inclusion criteria were the following: 1) age $>65$ years, 2) osteoporotic fracture or more, 3) pain score of at least 5 of ten, 4) ability to give informed consent. Patients were excluded if they had an infectious disease, tumor involvement of the vertebral to be treated, diagnosis is of multiple myeloma.

\subsection{Collection of Baseline Variables}

Baseline data collection included age, gender, weight and height. Outcome measures collected at baseline included a 0 - 10 rating of average pain (Numerous Rating Scale, NRS) during 24 hours, pain with exercise, and pain at rest and the modified 23-question ( the Roland-Morris Disability Questionnaire, RDQ) [8,9].

\subsection{Procedural Characteristics}

We escorted the patients to a fluoroscopy room after screening and written informed consent. All procedures were performed under strict aseptic conditions. Patients placed decubitus posture on fluoroscopy table. We used fluoroscopy for localization of the vertebral bodies to be treated. A 1-inch 25-gauge needle used to raise a wheel of $1 \%$ lidocaine subcutaneously. A 12-cm 22-gauge block needle placed into the skin at the site of the wheel and advanced under fluoroscopic guidance to the periosteum over the pedicle. (Figure 1) After infiltration with 1 $\mathrm{ml}$ of $1 \%$ lidocaine at the spots, we drilled vertebral bones until the marrow. When the cortex was penetrated,

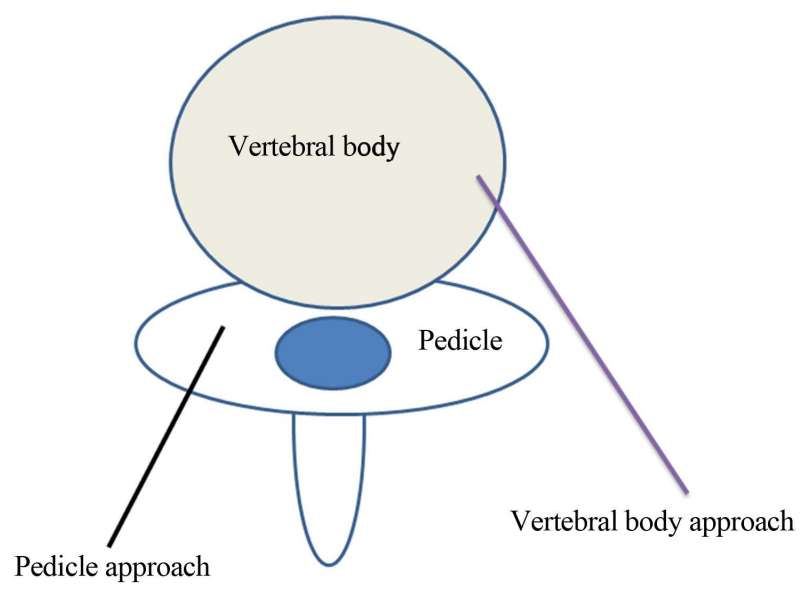

Figure 1. Pedicle approach and vertebral body approach. In this study, vertebral B.D. (Bone Drilling) was done by Pedicle approach. the marrow was aspirated from an attached syringe. A small account of contrast medium injected to verify that the needle tip was within the marrow. After stopping backflow from the needle, we removed the needle. We compressed the wound for several minutes.

\subsection{Outcome Measures and Analysis}

We assessed primary outcome measures in the NRS scores (average during the past 24-hours, with exercise, and at rest) and RDQ scores at day 0 and 3 following the drilling. Comparisons were made by using Wilcoxon rank sum test. Descriptive statistics determined by calculation of the mean and standard deviation (S.D.). Results presented as mean \pm S.D, and statistical significance defined as $\mathrm{P}<0.05$.

\section{Results}

\subsection{Patient Factors}

A total of 26 patients with 38 osteoporotic vertebral compression fractures were enrolled in this study. Of these 26 patients, 6 were male, and 20 were female. The mean age, body weight, and height of the patients were $79.9 \pm 5.7$ years, $51.5 \pm 9.5 \mathrm{~kg}$, and $149 \pm 10.3 \mathrm{~cm}$, respectively. Sixteen patients had 1 osteoporotic compression fracture. 8 patients had 2 osteoporotic compression fractures, and 2 patients had 3 osteoporotic compression fractures. The levels treated were $1 \mathrm{~T} 1$, five $\mathrm{T} 4$, two T5, two T8, two T10, eight L1, two L2, six L3, seven L4, two L5 and one S.

\subsection{Improvement in Function and Pain after Vertebral B.D.}

Among the 26 patients enrolled in this study, NSR and RDQ scores at day 0 and day 3 following the Vertebral B.D. are presented in Table 1. There were significant improvements in average NRS score during 24 hours, pain with exercise, and pain at rest at day 3 compared with baseline. $(\mathrm{P}<0.001)$ A significant improvement

Table 1. Improvement in Function and Pain after Vertebral B.D..

\begin{tabular}{cccc}
\hline & Baseline & Day 3 & P-Value \\
\hline NRS during the past 24 hours & $7.3 \pm 1.2$ & $4.6 \pm 1.4$ & $<0.001$ \\
NRS with exercise & $8.2 \pm 1.4$ & $4.2 \pm 2.7$ & $<0.001$ \\
NRS at rest & $6.0 \pm 2.3$ & $2.2 \pm 2.6$ & $<0.001$ \\
RDQ & $15.7 \pm 4.2$ & $7.3 \pm 2.2$ & $<0.001$ \\
\hline
\end{tabular}

B.D.: Bone Drilling; NRS, Numerous Rating Scale; RDQ: the RolandMorris Disability Questionnaire. P $<0.001$ vs corresponding value between baseline and day3 after the vertebral B.D.. Data are presented as mean \pm S.D.. 
noted in the RDQ scores at day 3 compared with baseline. $(\mathrm{P}<0.001)$

\section{Discussion}

Although B.D. had reported the alleviation of pain from 1890 [10], B.D. is a forgotten pain treatment in modern medicine. During attempted Vertebroplasty in patients with vertebral compression fracture, Kohashi et al. [11] accidentally found that drilling of the vertebral body alone elicited analgesia, even through injection of bone cement into vertebral marrow failed due to some reasons. Subsequently, the B.D. was effective for pain management in osteoarthritis [12]. A recent uncontrolled study reported the effectiveness of vertebral B.D. to be $87.5 \%$ [13]. B.D. for chronic pain was useful, and the analgesic effect continued for 30 - 45 weeks [14]. B.D. has been incorporated in The Guideline of Therapeutics for Pain Clinic in Japan [15].

A conventional B.D. often needs a marrow tap needle for hard bones and a drilling machine. In osteoporotic patients, careful drilling is necessary because a needle pierces easily and injuries tissues behind the bone. Probable complications of B.D. are hemorrhage, infection, ectopic tissue injury and fracture. We did not use a marrow tap needle and a drilling machine for decrease of the complications.

B.D. therapy is effective in the relief of bone marrow edema (bone bruise) [16]. According to the literatures [11-13], while B.D. into the bone marrow had an analgesic effect, B.D. within the cortex had no effect. Therefore, the aspiration of the bone marrow blood with medical mediators and receptors has speculated to contribute the alleviation of pain. The pain relief mechanism of the B.D. is still unclear. Further investigation requires to make clear the mechanism underlying between bone tissue pain and B.D.

\section{Conclusion}

Vertebral B.D. at the site of painful vertebral compression fractures attenuated the acute intractable pain and improved in the pain-related disability due to osteoporotic vertebral compression fractures.

\section{REFERENCES}

[1] P. Galibert, H. Deramond, P. Rostat and D. Le Gars, "Preliminary Note on the Treatment of Vertebral Angioma by Percutaneous Acrylic Vertebroplasty," Neurochirurgie, Vol. 33, No. 2, 1987, pp. 266-268.

[2] C. A. Klazen, P. N. Lohie, J. de Vries, F. H. Jansen, A. V. Tiebeek, M. C. Blonk, A. Vermans, W. J. van Rooij, M. C. Schoemaker, J. R. Juttmann, T. H. Lo, H. J. Verhaar, Y. van der Graaf, A. F. Muller, O. E. Elgersma, D. R. Halkema, H. Fransen, X. Janssen, E. Buskens and W. P.
Mali, "Vertebroplasty versus Conservative Treatment in Acute Osteoporotic Vertebral Compression Fractures (Vertos II ): An Open Label Randomized Trial,” Lancet, Vol. 376, No. 9746, 2010, pp. 1085-1092. http://dx.doi.org/10.1016/S0140-6736(10)60954-3

[3] D. Wardlaw, S. R. Cummings, J. Van Meirhaeghe, L. Bastian, J. B. Tillman, J. Ranstam, R. Eastell, P. Dhabi, K. Talmadge and S. Boonen, "Efficacy and Safety of Balloon Kyphoplasty Compared with Non-Surgical Care for Vertebral Compression Fracture (FREE): A Randomized Controlled Trial," Lancet, Vol. 373, No. 9668, 2009, pp. 1016-1024.

http://dx.doi.org/10.1016/S0140-6736(09)60010-6

[4] R. Buchbinder, R. H. Osborne, P. H. Ebeling, P. R. Ebeling, J. D. Wark, P. Mitchell, C. Wriedt, S. Graves and M. P. Staple, "A Randomized Trial of Vertebroplasty for Painful Oseteoporotic Vertebral Fractures," The New England Journal of Medicine, Vol. 361, No. 6, 2009, pp. 557-568. http://dx.doi.org/10.1056/NEJMoa0900429

[5] D. F. Kallmes, B. A. Comstock, P. J. Heagerty, P. J. Heagerty, J. A. Turner, D. J. Wilson, T. H. Daiamond, R. Edwards, L. A. Gray, L. Stout, S. Owen, W. Hollingworth, B. Ghdoke, D. J. Annesley-Williams, S. H. Ralston and J. G. Jarvik, “A Randomized Trial of Vertebroplasty for Osteoporotic Spinal Fractures,” The New England Journal of Medicine, Vol. 361, No. 6, 2009, pp. 569579. http://dx.doi.org/10.1056/NEJMoa0900563

[6] Y. Kohashi, T. Matsuura, E. Ishitani, K. Shin and Y. Sonoda, "The Experience of Decompression of Internal Pressure in Vertebra Body for Painful Osteoporotic Thoracolumbar Compression Fractures," Orthopaedic Surgery \& Traumatology, Vol. 49, 2006, pp. 833-839.

[7] W. Brinjikji, B. A. Comstock, L. Gray and D. F. Kallmes, "Local Anesthesia with Bupivacaine and Lidocaine for Vertebral Fracture Trial (LABEL): A Report of Outcomes and Comparison with the Investigational Vertebroplasty Efficacy and Safety Trial (INVEST)," AJNR, Vol. 31, No. 9, 2010, pp. 1631-1634.

http://dx.doi.org/10.3174/ajnr.A2145

[8] M. Roland and J. Fairbank, "The Roland-Morris Disability Questionnaire and the Oswestry Disability Questionnaire,” Spine, Vol. 25, No. 4, 2000, pp. 3115-3124. http://dx.doi.org/10.1097/00007632-200012150-00006

[9] A. T. Trout, D. F. Kallmes, L. A. Gray, B. A. Goodnature, S. L. Everson, B. A. Comstock and J. G. Javic, "Evaluation of Vertebroplasty with a Validated Outcome Measure, the Roland-Morris Disability Questionnaire,” AJNR, Vol. 26, No. 10, 2005, pp. 2652-2657.

[10] N. Smith, "Bone-Drilling in the Neighborhood of Inflamed Joints and Elsewhere,” BMJ, Vol. 1, 1890, p. 416. http://dx.doi.org/10.1136/bmj.1.1521.416

[11] Y. Kohashi, T. Matsuura, E. Ishitani, K. Shin and A. Okada, "The effect of decompression of internal pressure in vertebral body for painful osteoporotic vertebral compression fracture,” Orthopaedic Surgery \& Traumatology, Vol. 47, 2004, pp. 1589-1595.

[12] K. Shinjyo, "New Surgical Treatment of Osteoarthritis Based on Its New Pathogenesis," Central Japan Journal of Orthopaedic Surgery and Traumatology, Vol. 48, 2005, 
pp. 531-532.

[13] M. Ogihara and T. Akamine, "Clinical Effects of Transpedicular Core Decompression of Vertebral Body for Osteoprotic Vertebral Compression Fracture,” Pain Clinic, Vol. 31, 2010, pp. 489-495.

[14] S. Aida, N. Kuratani, Y. Ohhara, S. Amagasa and Z. Wajima, "Immediate Alleviation of Chronic Pain by Bone Drilling and Probable Involvement of Bone Tissue in Pain Sensitization,” BMJ Case Repots, 2011. http://dx.doi.org/10.1136/bcr.07.2010.3173

[15] Committee for the Therapeutic Guideline of Japan Society of Pain Clinicians, "I-28 Marrow Decompression," In: K. Hanaoka, Ed., The Guideline of Therapeutics for Pain Clinic, Version 3, Shinko-Koeki, Tokyo, 2010, pp. 52-54.

[16] S. Santini, A. Rebeccato and R. Schiavon, "Percutaneous Drilling for Chronic Heel Pain," Journal of Foot and Ankle Surgery, Vol. 42, No. 5, 2003, pp. 296-301. http://dx.doi.org/10.1016/j.jfas.2003.08.002

\section{Abbreviations}

RCTs: Randomized Controlled Trials

B.D.: Bone Drilling

NRS: Numerous Rating Scale

RDQ: the Rolland-Morris Disability Questionnare

S.D.: Standard Deviation 